$$
\begin{aligned}
& \text { AN/F) T/CP--81539 } \\
& \text { Conf-940135--1 }
\end{aligned}
$$

\title{
APPLICATION OF LASER SCATTERING FOR DETECTION OF SURFACE AND SUBSURFACE DEFECTS IN SI 3N4 COMPONENTS
}

by

\author{
J. Scott Steckenrider, William A. Ellingson \\ Argonne National Laboratory
}

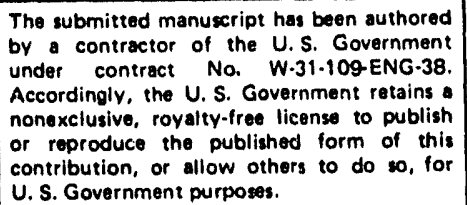

\section{DISCLAIMER}

\begin{abstract}
This report was prepared as an account of work sponsored by an agency of the United States Government. Neither the United States Government nor any agency thereof, nor any of their employees, makes any warranty, express or implied, or assumes any legal liability or responsibility for the accuracy, completeness, or usefulness of any information, apparatus, product, or process disclosed, or represents that its use would not infringe privately owned rights. Reference herein to any specific commercial product, process, or service by trade name, trademark, manufacturer, or otherwise does not necessarily constitute or imply its endorsement, recommendation, or favoring by the United States Government or any agency thereof. The views and opinions of authors expressed herein do not necessarily state or reflect those of the United States Government or any agency thereof.
\end{abstract}

Paper submitted to the American Ceramics Society's 18th Annual conference on Composites and Advanced Ceramics in Cocoa Beach, Florida, January 9-14, 1994.

*Work sponsored by the Defense Sciences Offices/Materials Division/ARPA 


\title{
APPLICATION OF LASER SCATTERING FOR DETECTION OF SURFACE AND SUBSURFACE DEFECTS IN SI3N4 COMPONENTS
}

\author{
J. Scott Steckenrider \\ William A. Ellingson \\ Argonne National Laboratory \\ 9700 South Cass Avenue \\ Argonne, II 60439
}

\section{ABSTRACT}

$\mathrm{Si}_{3} \mathrm{~N}_{4}$ ceramics are currently primary materials of choice in structural applications because of their mechanical and thermal properties. However, the lifetimes of these ceramic components especially those that experience contact fatigue (e.g., bearings) - are most affected by defects such as voids, inclusions, or microstructural variations in the surface or near-surface $(<200 \mu \mathrm{m})$ region. Thus, a technique is desired for the rapid detection and quantification of both surface and subsurface defects. Because $\mathrm{Si}_{3} \mathrm{~N}_{4}$ can partially transmit visible (and IR) light, we have applied laser scattering to the analysis of various $\mathrm{Si}_{3} \mathrm{~N}_{4}$ materials in several component shapes. Using polarization techniques to independently analyze surface and subsurface material, we have detected defects as deep as $100 \mu \mathrm{m}$ below the surface. Other methods such as X-ray CT and SEM analysis have further substantiated these results.

INTRODUCTION 
As technology has advanced, so has the requirement for stronger, longer-lasting materials capable of functioning in environments more severe than traditional materials permit. Thus, materials selection has become a key stepping stone in the paih to progress. In response to this need, researchers have begun to consider ceramics for applications once reserved only for metals and alloys. Because of their mechanical and physical properties, such as higher stiffness, corrosion and wear resistance, and greater thermal stability, silicon nitride ( $\left.\mathrm{Si}_{3} \mathrm{~N}_{4}\right)$ ceramics are considered the materials of choice to replace steels in such applications as contact rolling elements (e.g., bearings), where stiffness and wear resistance play a key role[1-3]. There is also interest in these ceramics for high-temperature turbine components where increased thermal stability is critical. For any such applications, the most critical portions of the ceramic component, i.e., those undergoing the highest stresses during operation, are the surface or near-surface (usually to depths of $<200 \mu \mathrm{m}$ ) regions. Thus, defects generated in this region, whether during processing, machining, or use, must be detected as early as possible to minimize cost (for processing or machining induced damage[4]) or to reduce or eliminate on-line failure of the ceramic component (for defects induced during use).

Because the smallest critical defects are located on or just beneath the surface, traditional methods of nondestructive evaluation (NDE) - such as radiography, including high-resolution Xray CT, and ultrasonics - are not well suited for defect detection. High resolution X-ray CT is mainly sensitive to interior (bulk) defects and is therefore relatively insensitive to surface/nearsurface defects [5]. Ultrasonics on the other hand can be highly sensitive to the surface/nearsurface region through the use of Surface Acoustic Waves (SAWs). However, to provide sufficient spatial resolution, a scanning SAW microscope must be used, and this instrument is primarily intended for flat surfaces, not the curvatures and complex geometries associated with such ceramic components as rolling contact fatigue elements, turbine blades, etc.[6]. In addition, determination of microstructural anisotropy requires that the part be repetitively scanned in several directions, necessitating additional time and effort. 
Previous researchers have focused considerable effort into the non-contact characterization of machined surfaces of metals using elastic optical scattering (predominantly laser-based) techniques[7-9]. These methods have been shown to be effective at providing a non-contact method of determining surface roughness on scales of $R_{a}$ from $0.001 \mu \mathrm{m}$ to $30 \mu \mathrm{m}$. However, these techniques do not directly provide information regarding the spatial distribution of the surface roughness. In addition, they have dealt predominantly with metallic surfaces, where optical penetration of the surface is essentially non-existent. Any material has a characteristic "skin depth", as a function of optical frequency, to which light can penetrate beneath the surface because of the finite absorption of the material. Thus, interaction between light and material, which is the source of all optical scatter, occurs not only at the surface but in the subsurface as well. For metals, this skin depth is only a few nanometers at most for visible wavelengths, so that scatter is considered to emanate entirely from the surface. However, for many $\mathrm{Si}_{3} \mathrm{~N}_{4}$ ceramics, the skin depth can be $\geq 100 \mu \mathrm{m}$ in the visible spectrum, depending on second phase composition[10]. Thus, the optical scatter signature can provide information on both surface and subsurface regions. EXPERIMENTAL PROCEDURE

The combined implementation of Fourier and polarizing optics required for this work has been presented elsewhere[10] and is illustrated in Fig. 1. A $35 \mathrm{~mW}$ polarized He-Ne laser was used as the light source. (For purposes of illustration, a spherical specimen with corresponding spherical expansion and illumination lenses is shown in the figure. However, for cylindrical rod inspection, cylindrical lenses were used, while for flat surface inspection, a collimating lens system with $\mathrm{a} \approx 1 \mathrm{~mm}$ beam diameter was used.) To avoid astigmatic aberration in the specularly reflected beam normal incidence to the specimen was required. A polarizing beamsplitter (PBS) was therefore positioned to reflect the laser light toward the specimen. This also served to separate the surface and subsurface scatter. With the detection system located as shown in the figure, surface scatter - which was relatively unshifted in polarization - was rejected by the PBS, while half of the subsurface scatter - which is of random polarization - was passed to the detection system. An 
analyzing polarizer, which has a higher efficiency (1000:1) than the PBS (100:1), was inserted in the detection leg to further improve the signal-to-noise ratio.

For surface analysis, a quarter-wave plate was inserted between the PBS and the specimen to rotate the surface reflected light polarization $90^{\circ}$, thereby allowing it to pass through the PBS to the detection system. This still allowed $50 \%$ of the subsurface scatter to reach the detector, but the surface scaiter was still sufficiently intense as to overpower the subsurface scatter in all tested cases. Scatter patterns were detected by a CCD camera with a macro lens focused at the Fourier plane, as shown in Fig. 1. Because of configurational limitations (i.e. the limited numerical aperture of the detection system), the Fourier spectrum was limited to spatial frequencies of $2 \mathbf{x}$ $10^{5} \mathrm{~m}^{-1}$ or less, which corresponds to surface/subsurface defects of $5 \mu \mathrm{m}$ or larger. Although this is sufficient resolution for the current experiments, if necessary this limitation can be overcome to some extent by more efficient arrangement of the detection optics. This would increase the numerical aperture to achieve spatiai resolution approaching $1 \mu \mathrm{m}$.

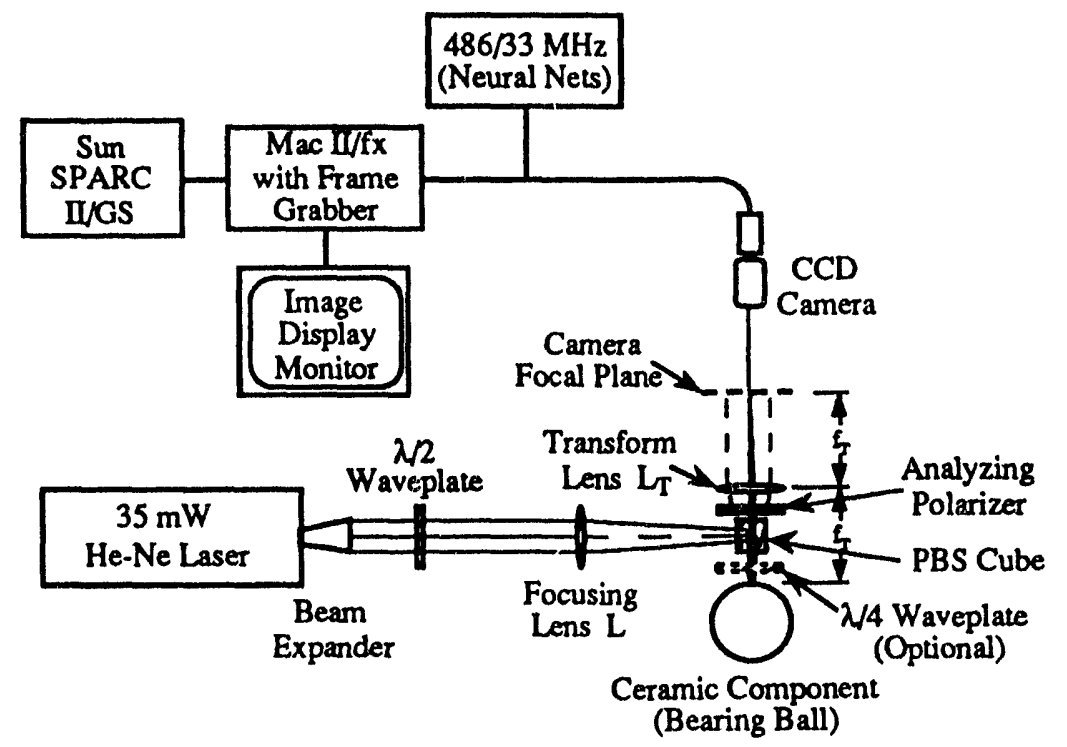

Figure 1. Experimental configuration for Fourier analysis of laser scatter from surface and subsurface regions.

While $\mathrm{Si}_{3} \mathrm{~N}_{4}$ ceramics are the materials of greatest interest for the current effort, each of the many ceramics manufacturers produces an $\mathrm{Si}_{3} \mathrm{~N}_{4}$ material with slightly different composition (because of the need for a small amount of second phase material in the sintering process to 
maximize densification). Four relatively common materials developed specifically for rolling contact applications were used in this effort: CERBEC NBD-200 (using $\mathrm{MgO}$ and $\mathrm{Y}_{2} \mathrm{O}_{3}$ as the second-phase materials), Toshiba TSN-03H (using $\mathrm{Al}_{2} \mathrm{O}_{3}$ as the second-phase material), CERCOM LP (using $\mathrm{Y}_{2} \mathrm{O}_{3}$ and $\mathrm{Al}_{2} \mathrm{O}_{3}$ as the second-phase materials), and Garrett $\mathrm{GS}-44$ (of undetermined second-phase composition). To expedite sample preparation, and to establish the breadth of applicability of this technique, specimens were examined in flat bar, spherical ball, and cylindrical rod shapes.

The first specimens investigated were those with known surface defects. To simulate a surface spall in a bearing ball, as well as to provide a highly reproducible defect, a Vickers indenter was used to create four indents of different sizes in a 12.7-mm-diameter NBD-200 bearing ball. The ball was supplied in Grade 5, indicating a surface finish $R_{a}$ value of $<0.013 \mu \mathrm{m}$. Each of the four indents was generated with a different load, thereby producing square indents with sides measuring $\approx 50 \mu \mathrm{m}(5 \mathrm{~kg}$ load $), \approx 21 \mu \mathrm{m}(1 \mathrm{~kg}$ load $), \approx 16 \mu \mathrm{m}(0.5 \mathrm{~kg}$ load $)$, and $\approx 11 \mu \mathrm{m}(0.3 \mathrm{~kg}$ load).

To approximate sensitivity limits for subsurface defect detection, it is first important to determine the optical properties of the materials of interest. These are presented in Fig. 2 for NBD200 and TSN-03H. Figure 2a shows the optical transmission properties of the two materials as a function of optical wavelength. However, these measurements were made using a Varian CARY Model 5 spectrophotometer with a small numerical aperture, thereby neglecting any scattering contribution to the effective loss in transmission. Figure $2 b$ is a plot of transmission versus component thickness, at a single wavelength, measured with a step wedge of the ceramic and an integrating sphere to account for scattering losses in transmission. By comparing the two graphs, one can see that at least at the wavelength of interest $(0.6328 \mu \mathrm{m})$, the plot of Fig. $2 \mathrm{a}$ underestimates transmission by at least one order of magnitude. Thus, one can predict that light penetration should be sufficient to detect defects to depths of several tens of micrometers in the visible wavelengths, and potentially deeper in the IR. 


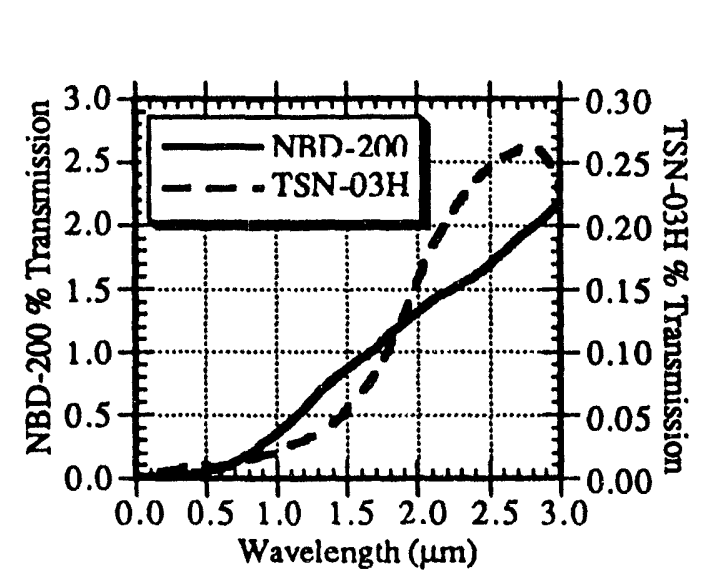

a)

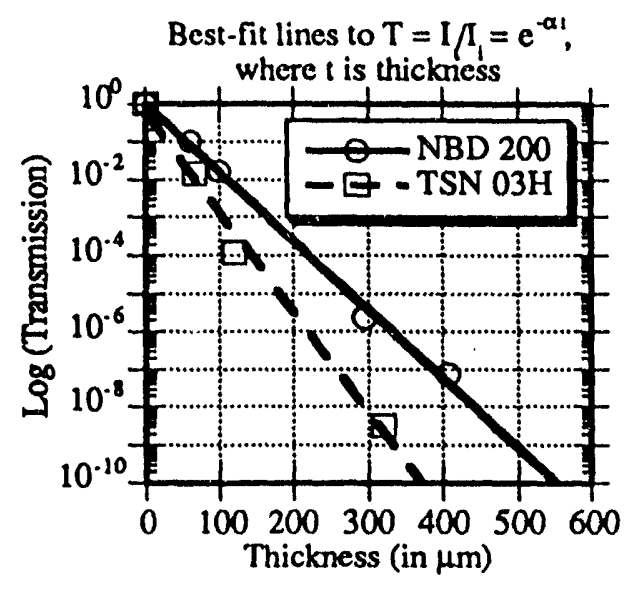

b)

Figure 2. Optical transmission properties of NBD-200 and TSN-03H Si3N4 ceramics as a function of (a) optical wavelength (through $\mathrm{a} \approx 66-\mu \mathrm{m}$-thick specimen) and (b) specimen thickness $(\lambda=0.6328 \mu \mathrm{m})$.

There are two primary types of subsurface defects to consider: inclusions and voids. Inclusions are primarily a product of processing, in which an agglomeration of second phase material is present with dimensions larger than some critical size (usually dictated by the application for which the component is made). Fortunately, not only are these defects less of a problem than voids, as they produce less of a stress concentration, but processing of $\mathrm{Si}_{3} \mathrm{~N}_{4}$ is sufficiently advanced so as to essentially avoid such defects. The general category of voids, on the other hand, describes any case in which a material-air interface exists within a specimen. This can encompasses a variety of defect types, including " $0-D$ " porosity (where the pore size is significantly smaller than the material grain size), "1-D" and "2-D" cracks (viewed parallel and normal to the crack plane, respectively), and " $3-\mathrm{D}$ " isolated voids (where the void size is significantly larger than the grain size). However, because porosity is generally not an isolated defect causing a localized failure, but rather a distribution of defects resulting in a change in overall mechanical properties, it will be considered under microstructural characterization.

To determine the limits of subsurface defect detection, a flat polished NBD-200 bar $3 \mathrm{~mm}$ $\times 4 \mathrm{~mm} \times 20 \mathrm{~mm}$ was used. To simulate a subsurface void or lateral (parallel to the surface) crack, 
1.5-mm-diameter holes were drilled to almost the full thickness of the bar so that the remaining "skin" of ceramic covering the front surface of the hole was of a known dimension. The bar's front surface was illuminated with a 1-mm-diameter collimated beam, and the scatter pattern was analyzed for subsurface scatter under crossed-polarization detection as the bar was scanned laterally.

The final area of investigation was that of subsurface microstructure characterization. To demonstrate this capability, two examples were chosen. First, a 4.75-mm (3/16") diameter bearing ball of GS-44 Si3 44 was scanned for subsurface variations. Second, a $25 \mathrm{~mm} \times 25 \mathrm{~mm} \times 6 \mathrm{~mm}$ specimen of uniaxially pressed CERCOM LP Si3 44 (pressed along the $6 \mathrm{~mm}$ dimension) was examined on sides both along and normal to the direction of pressing for indications of microstructural anisotropy.

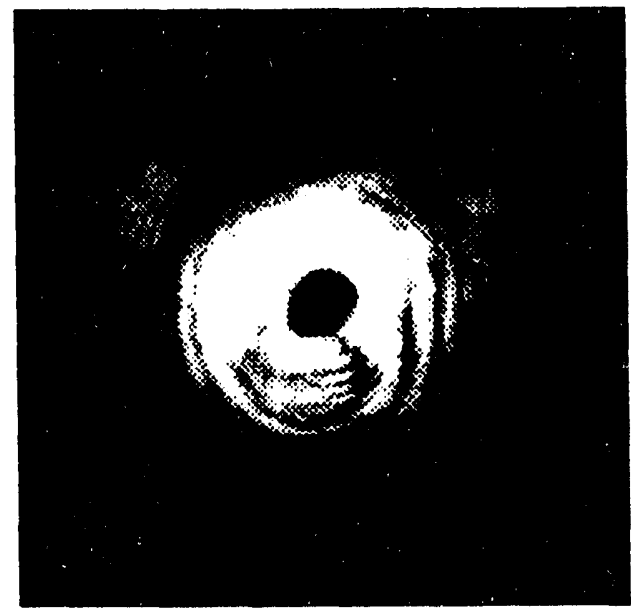

a)

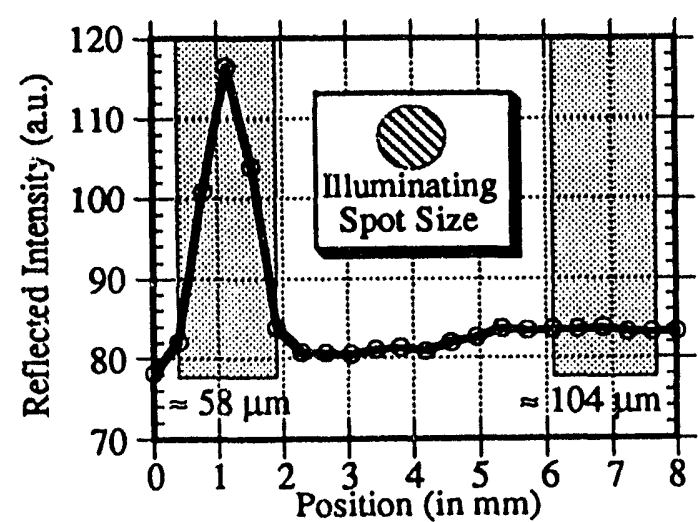

b)

Figure 3. Illustration of (a) Fourier scatter pattern for Vickers indent in a 12.7-mm-diameter NBD-200 bearing ball at $0.3 \mathrm{~kg}$ load and (b) data plot for subsurface void detection.

\section{RESULTS AND DISCUSSION}

\section{Surface Defect Detection}

The detected Fourier scatter pattern for the smallest surface indent is shown in Fig. 3a. Because the theoretically predicted Fourier pattern for a square aperture is known (a sinc function), this pattern can be used to estimate the actual size, shape, and orientation of the surface defect. For 
the case shown, this estimation corresponds to a square scatterer with sides of $\approx 16 \mu \mathrm{m}$. Although this differs from the microscopically measured dimension by a factor of 1.5 , the same factor is present in all four indents, indicating that the effective defect size is larger (possibly because of surface deflection around the indent caused by plastic deformation). Even so, this method has proven capable for surface defect detection and quantification for dimensions $\geq 10 \mu \mathrm{m}$.

Subsurface Defect Detection

While the detectability of surface defects is rather straightforward and predictable, detection of subsurface defects is more complicated. In order to predict whether these can be seen, it is necessary to examine the interactions which give rise to subsurface scatter. The major contributor to scatter in these $\mathrm{Si}_{3} \mathrm{~N}_{4}$ materials is grain boundary reflections. If the material were $100 \%$ pure $\mathrm{Si}_{3} \mathrm{~N}_{4}$, there would be relatively little interaction between grains, and hence relatively little scatter. However, there is a second phase sintering aid present in all of the $\mathrm{Si}_{3} \mathrm{~N}_{4}$ materials tested, and since this second phase has a slightly different index of refraction ( $\Delta n \approx 0.5$ or less), reflection at the interface is increased causing a noticeable scatter from the material. (In addition, it is because of the variation in second phase material and concentration from manufacturer to manufacturer that optical transmission properties of various $\mathrm{Si}_{3} \mathrm{~N}_{4}$ materials are sn widely varied.) Now when a subsurface crack or void is present in the material, a $\mathrm{Si}_{3} \mathrm{~N}_{4}$-air interface is created with a substantially larger mismatch in index of refraction $(\Delta n \approx 1)$ at the grain boundary, so that a larger amount of the light incident on that boundary is reflected. Thus if all other characteristics of the material remain unchanged, there will be an increase in the detected scattered intensity over a region of the specimen which contains a subsurface defect.

The flexure bar used to simulate subsurface voids had hole depths of $58 \mu \mathrm{m}$ and $104 \mu \mathrm{m}$ measured microscopically to the center of each hole. Figure $3 \mathrm{~b}$ shows the plot of total scattered intensity (within the $2 \times 10^{5} \mathrm{~m}^{-1}$ spatial bandwidth of the Fourier system), normalized by the number of imaging pixels, as a function of position across the bar. As is clearly seen, detection of a "void" $54 \mu \mathrm{m}$ below the surface was accomplished well outside the noise range, while the 104 $\mu \mathrm{m}$ subsurface defect was not seen. Combined with other results for both NBD-200 and TSN- 
$03 \mathrm{H}$ (not presented for brevity), this indicates a maximum detection depth of $\approx 100 \mu \mathrm{m}$ for the 633 $\mathrm{nm}$ wavelength in NBD-200. (The maximum detection depth is slightly less for TSN-03H, as would be expected from Fig. 2.) However, this maximum depth of sensitivity should be greatly improved by using IR illumination, because of its greater depth of optical penetration.

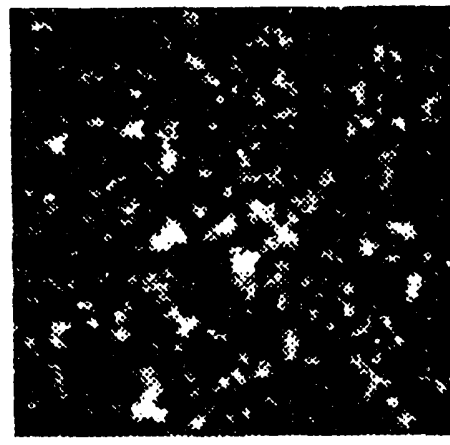

a)

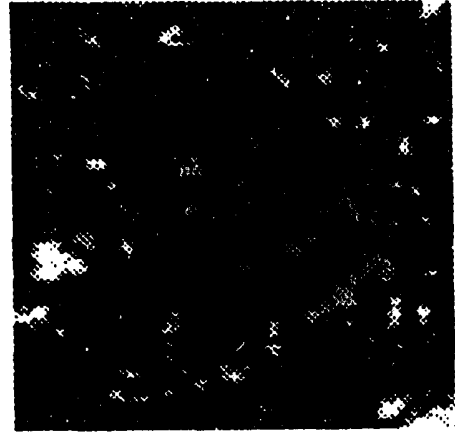

b)

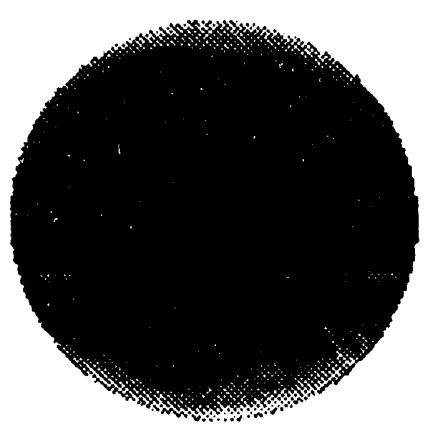

c)

Figure 4. Scatter patterns produced by illumination of a) polar and b) equatorial regions of a 3/16" diameter Garrett GS-44 bearing ball. Also shown is an X-ray CT image of the ball showing lower density in the polar regions.

Subsurface Microstructure Characterization

To measure the detectability of density variations (caused by subsurface porosity), a GS-44 bearing ball was scanned circumferentially from pole to equator. (By convention, the two points on the ball surface whose normals are along the uniaxial pressing direction used in forming the ball will be called "poles," while the circumferential band equidistant from these poles will be called the "equator.") By examining the frequency content of the resulting scatter pattern images, shown in Fig. 4, we determined that in the porous region, the "speckle" size in the scatter image was noticeably larger. This would indicate a smaller lateral extent of the illumination spot at the ball's surface, as would be expected for a porous material (where reflection off of the pores acts to reduce the spread of light in the subsurface. We were therefore able to delineate distinct regions of low density (i.e., high porosity) extending $\approx 30^{\circ}$ from the poles. (Automated detection of these porous regions will be discussed in the following paper [11].) The same ball was further examined with high-resolution microfocus X-ray CT (see Fig. 4c), and subsequently destructively 
examined by optical photomicroscopy. Both supporting methods revealed the same low-density regions.

a)

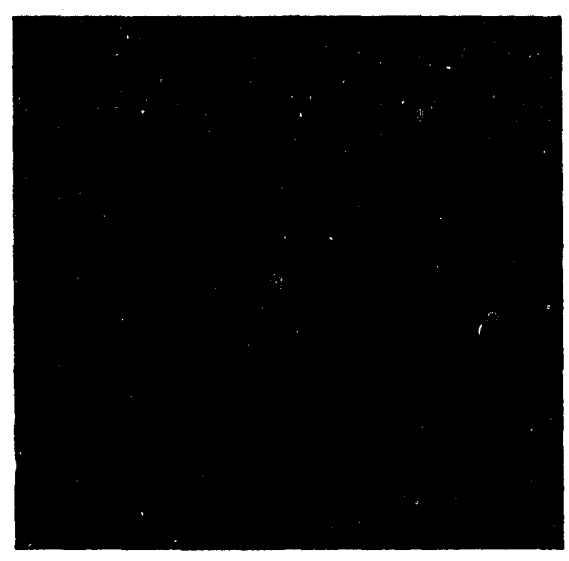

b)

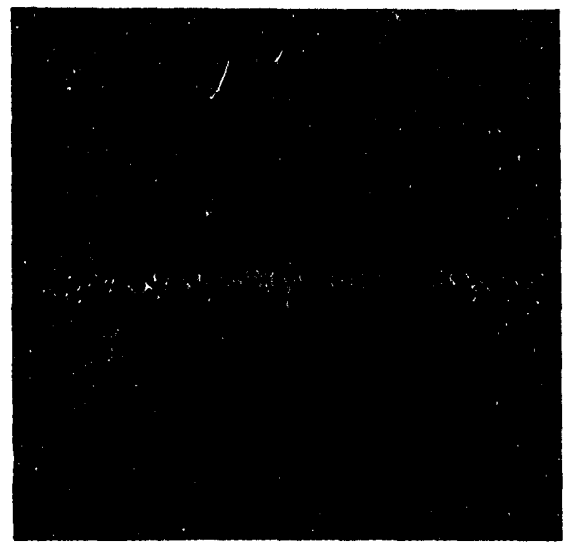

Figure 5. Photographs of Fourier scatter patterns produced by (a) face (isotropic) and (b) side (anisotropic) of CERCOM LP uniaxially pressed $\mathrm{Si}_{3} \mathrm{~N}_{4}$ ceramic.

A second example of laser scatter sensitivity to microstructural variations is shown in Fig. 5. Figure 5a shows the Fourier scatter pattern detected from the face of the uniaxially pressed CERCOM LP specimen, while Fig. 5b shows the pattern detected from one of the specimen's sides. Clearly, the side scatter pattern shows a significant orientation that is not present in the isotropic pattern from the face. This anisotropy causes a $25 \%$ difference in mechanical properties of the bulk material between these two directions, as measured ultrasonically by the manufacturer. This anisotropic orientation was caused by a preferential alignment of grains perpendicular to the pressing direction, as substantiated by SEM analysis (see Fig. 6). Furthermore, scanning the illuminating laser beam along the $25 \mathrm{~mm}$ length of this side revealed a variation in this preferential orientation from $-20^{\circ}$ to $+12^{\circ}$ that was not observed in the ultrasonic analysis. 


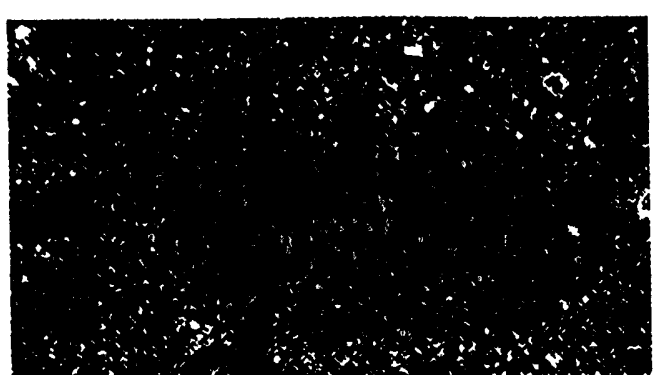

a)

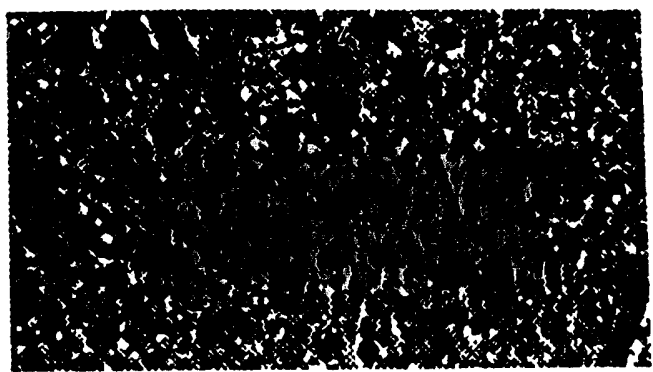

b)

Figure 6. SEM photomicrographs of the a) face (viewed parallel to pressing direction) and b) side (viewed normal to pressing direction) of a uniaxially pressed CERCOM LP specimen.

\section{CONCLUSIONS}

At present, $\mathrm{Si}_{3} \mathrm{~N}_{4}$ ceramics are a primary material of choice as replacements for traditional materials in rolling contact fatigue (and other) applications because of their mechanical and thermal properties. Lifetimes of $\mathrm{Si}_{3} \mathrm{~N}_{4}$ components that experience contact fatigue (e.g., bearings) are significantly affected by defects (i.e., voids, inclusions, or microstructural variations) in the surface or near-surface $(<200 \mu \mathrm{m})$ region. By taking advantage of Si3N4's ability to partially transmit visible (and IR) light, we have developed an optical technique for the rapid detection and quantification of defects in both surface and subsurface locations, as well as for characterization of subsurface microstructure. We have applied this laser scattering method to the analysis of various $\mathrm{Si}_{3} \mathrm{~N}_{4}$ materials in several component shapes. Using polarization techniques to independently analyze surface and subsurface material, we have detected surface defects, such as Vickers indent markings, in sizes ranging from 10 to $50 \mu \mathrm{m}$, and subsurface defects, such as simulated voids, as deep as $100 \mu \mathrm{m}$ below the surface. In addition, subsurface microstructure, in the form of locally high porosity and variations in grain orientation, has been characterized. These results have further been substantiated by other methods such as high-resolution X-ray CT and SEM analysis. Present work will include analysis of detection sensitivity to Hertzian cracks and creep cavitation damage.

\section{ACKNOWLEDGMENTS}

The authors wish to acknowledge the support granted them by the Defense Sciences Office/Materials Division/ARPA. 


\section{REFERENCES}

1. Y. Nishihara, H. Nakashima, N. Tsushima, and S. Ito, "Factors That Affect Rolling Contact Fatigue Life of Ceramics and Rolling Contact Fatigue Life of Ceramic Balls and Rollers," ASME paper 90-GT-377, Brussels, Belgium (1990).

2. H. Takebayashi, T.M. Johns, K. Rukkaku, and K. Tanimoto, "Performance of Ceramic Bearings in High-Speed Turbine Application," Society of Automotive Engineers, paper 901629, Milwaukee, WI (1990).

3. J.F. Chudecki, "Ceramic Bearings - Applications and Performance Advantages in Industrial Applications," SAE Technical Paper Series 891904 (1989).

4. Konig, W. and Popp, M. "High precision Machining of Advanced Ceramics," in Third International Symposium on Ceramic Materials and Components for Engines, Las Vegas, NV, Nov. 27-30, 1988, V.J. Tennery, ed., published by Am. Cer. Soc., pp. 1159-1224.

5. E.A. Sivers, D.L. Holloway, W.A. Ellingson, and J. Ling, "Development and Application of Local 3-D CT Reconstruction Software for Imaging Critical Regions in Large Ceramic Turbine Rotors", in Review of Progress in QNDE, Vol. 12, eds. D.O. Thompson and D.E. Chimenti (Plenum, New York, 1993), pp. 357-364.

6. C.-H. Chou, P. Parent, and B.T. Khuri-Yakub, "Acoustic Microscopy with Mixed Mode Transducers", in Review of Progress in QNDE, Vol. 8, eds. D.O. Thompson and D.E. Chimenti (Plenum, New York, 1989), pp. 865-871.

7. J.C. Stover, Optical Scattering Measurement and Analysis (McGraw-Hill, New York, 1990).

8. T.V. Vorburger and E.C. Teaque,Optical Techniques for On-Line Measurement of Slirface Topography, Prec. Eng. 3(2) (1981), pp. 61-83.

9. J.M. Bennett and L. Mattson, Introduction to Surface Roughness and Scattering (Optical Society of America, Washington, DC 1989).

10. W.A. Ellingson, D.M. Ayaz, M.P. Brada, and W. O'Connell, "Detection of Subsurface Defects in Machined Silicon Nitride Ceramics by Optical Scattering Methods", in Machining of Advanced Materials, NIST Special Publication 847, Washington DC (1993), pp 147-157. 
11. M. C. Stinson, O. W. Lee, J. S. Steckenrider and W. A. Ellingson, "Recognition Of Subsurface Defects In Machined Ceramics By Application Of Neural Networks To Laser Scatter Patterns", in Ceramic Engineering and Science Proceedings, Amer. Cer. Soc., 1994. 


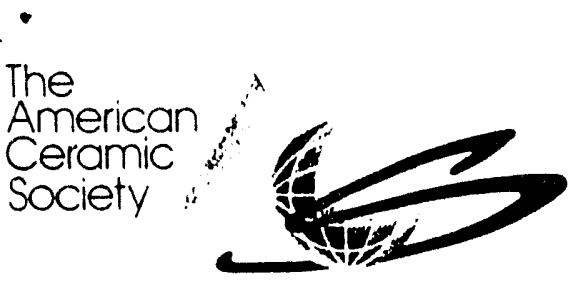

October 22, 1993

Dr. J. Scott Steckenrider

Argonne National Laboratory

Bldg. 212, 9700 South Cass Ave.

Argonne, IL. 60439

Dear Dr. Steckenrider:

We have had an overwhelming response to our Call for Papers for the American Ceramic Society's 18th Annual Meeting \& Exposition to be held in Cocoa Beach, Florida, January 9-12, 1994. We have identified approximately 210 papers to be presented as oral and/or poster presentations.

I am pleased to inform you that the program committee has selected your paper for presentation. Your paper "Application of Laser Scattering for Detection of Surface and Subsurface Defects in $\mathrm{Si}_{3} \mathrm{~N}_{4}$ Components" is scheduled to be given Tuesday, January 11, 1994 from 9:00-9:20 a.m.. You will be presenting your paper in the Sawgrass Room- Hilton Hotel.

Enclosed are several handouts of information which will be helpful as you prepare your presentation. This information is issued by the Society.

As a presenting author, you must register for the meeting and pay the appropriate meeting registration fee. If you are a member of the Society, you are expected to get your meeting and hotel registration information through the December BULLETIN. If you are not a member of the Society, the Society will mail you meeting and hotel registration information. As a limited number of hotel rooms are being held at a special rate for attendees of this meeting, I advise you to pre-register for the meeting and reserve your hotel room as soon as possible.

The Society will provide in each technical session room a $35 \mathrm{~mm}$ projector, overhead projector, screen, microphone, and electric pointer. Any additional equipment (e.g. VCR and monitor) is at the author's expense.

Your slides should be in a slide try before going to the technical session room to present your paper. The Society will have a room set for authors who use slides to preview their slides. You are encouraged to stop there and preview your slides. Please do not use glass slides. The March "Official Program" (September for Congress) issue of the BULLETIN will give you the location of lite Author Preview Room.

If you will be unable to attend the meeting, please notify me as soon as possible.

Thank you for your participation in 18th Annual Cocoa Beach Conference and Exposition, January 9-14, 1994. If you have any questions, feel free to contact me at the above address and phone number.

Sincerely,

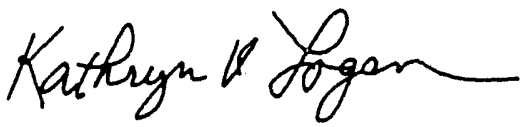

Program Chair

Enclosure

KVL/jrb

735 Ceramic Place

Westerville, Ohio 43081.8720

$614 \cdot 890 \cdot 4700$

TWX: 7101109409 

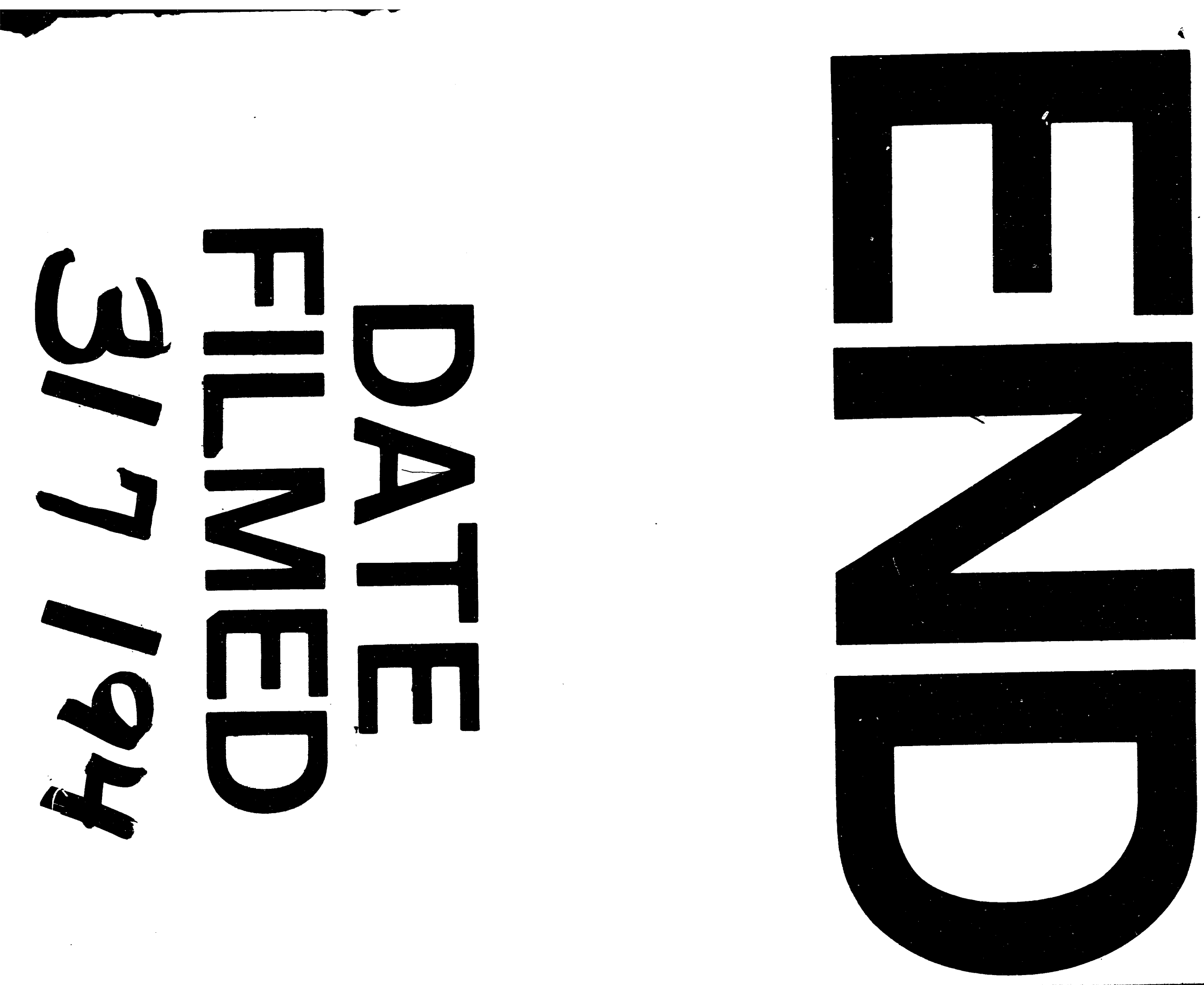
